\title{
CHARACTERISTICS AND SURGICAL OUTCOMES OF PATIENTS UNDERGOING DACRYOCYSTORHINOSTOMY IN KASHMIR
}

\author{
Syed Heena Kubravi' ${ }^{1}$, Syed Tariq Qureshi², Ejaz Akbar ${ }^{3}$, Shah Nawaz ${ }^{4}$, Khalid Kawoosa 5 \\ ${ }_{1}^{1}$ Postgraduate, Department of Ophthalmology, Government Medical College, Srinagar. \\ 2 Professor and HOD, Department of Ophthalmology, Government Medical College, Srinagar. \\ ${ }_{3}^{3}$ Associate Professor, Department of Ophthalmology, Government Medical College, Srinagar. \\ ${ }^{4}$ Lecturer, Department of Ophthalmology, Government Medical College, Srinagar. \\ 5 Senior Resident, Department of Paediatrics, SKIMS, Srinagar.
}

ABSTRACT

\section{BACKGROUND}

To study the pre- and post-operative characteristics and evaluate the surgical outcomes in patients undergoing external dacryocystorhinostomy for nasolacrimal duct obstruction with or without any previous episodes of dacryocystitis.

\section{MATERIALS AND METHODS}

This hospital based study was carried out at the Postgraduate Department of Ophthalmology, Government Medical College, Srinagar. A series of 76 patients with nasolacrimal duct obstruction, who underwent external dacryocystorhinostomy were studied. The preoperative evaluation included the following parameters: age, gender, residence, occupation, duration of symptoms, history of previous dacryocystitis, previous DCR, side of obstruction and presence of any other diseases (Systemic or ocular). Patients were examined at 1 week, 1 month, 3 months and 6 months following surgery. Surgical success was determined by the postoperative patency on syringing and resolution of symptoms at the end of six months. Patient satisfaction and complication rates were also assessed.

\section{RESULTS}

Out of the 76 patients evaluated, 42 were females and 34 were males. The mean age of patients was $58.6 \pm 14$ years. The mean duration of symptoms was 2.7 years. Left sided obstruction was more common (41 patients) than right-sided obstruction (33 patients). Bilateral obstruction was present in 2 patients; 30 patients had previous history of dacryocystitis, while 46 patients had no such history. The success rate was $88.4 \%$ for patients without previous history of dacryocystitis and $83.3 \%$ for patients with previous history of dacryocystitis.

\section{CONCLUSION}

The nasolacrimal duct obstruction is commoner in females than males in Kashmiri population. External dacryocystorhinostomy is an efficacious, safe and cost-effective treatment for the nasolacrimal duct obstruction. The surgical outcome is similar in patients with and without any previous history of dacryocystitis. The complication rate is low and overall patient satisfaction is high.

\section{KEYWORDS}

Nasolacrimal Duct Obstruction, Dacryocystorhinostomy, Dacryocystitis.

HOW TO CITE THIS ARTICLE: Kubravi SH, Qureshi ST, Akbar E, et al. Characteristics and surgical outcomes of patients undergoing dacryocystorhinostomy in Kashmir. J. Evolution Med. Dent. Sci. 2016;5(93):6879-6882, DOI: 10.14260/jemds/2016/1555

\section{BACKGROUND}

Nasolacrimal Duct Obstruction (NLDO) is one of the commonest cause of epiphora. It is more frequent in females. It may occur due to idiopathic stenosis, naso-orbital trauma or in granulomatous diseases like Wegener granulomatosis and infiltrating nasopharyngeal tumours. ${ }^{1}$

Dacryocystorhinostomy (DCR) is the standard treatment for NLDO. Other techniques include intubation, stent insertion and balloon dilatation. Broadly, there are two types of DCR: External and Endoscopic DCR.

Financial or Other, Competing Interest: None.

Submission 15-10-2016, Peer Review 10-11-2016,

Acceptance 16-11-2016, Published 21-11-2016.

Corresponding Author:

Dr. Syed Heena Kubravi,

H. No. 178, Botashah Colony,

Lal Bazar, Srinagar-190023,

Jammu and Kashmir.

E-mail: syedheenak@gmail.com

DOI: $10.14260 /$ jemds/2016/1555

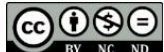

External dacryocystorhinostomy involves anastomosing the lacrimal sac to the nasal mucosa of the middle nasal meatus. Endoscopic procedures include laser dacryoplasty and microdrill dacryoplasty, which allow physiology of lacrimal draining system to be preserved intact. Advantages over external DCR include the lack of a skin incision, shorter operating time, minimal blood loss and less risk of cerebrospinal fluid leakage. ${ }^{2,3}$ However, success rates of both the procedures are almost similar and may range from $63 \%$ to $97 \%{ }^{4}$

Factors such as surgical variability, patient demographics and lack of standardised outcomes in literature may be responsible for the wide range of success rates. ${ }^{5}$ External DCR is still the treatment of choice in certain cases, in which endoscopic techniques are contraindicated (e.g. after dacryocystitis) or in failed cases requiring revision surgery. ${ }^{2}$

Various studies conducted have shown that surgical success co-relates with factors like patient age, duration of obstruction and presence or absence of previous episodes of dacryocystitis. $6,7,8$ 
The aim of this study was to evaluate the pre- and postoperative characteristics and surgical outcomes in patients who underwent DCR in our tertiary care centre.

\section{MATERIALS AND METHODS}

This study was conducted in the Postgraduate Department of Ophthalmology, Government Medical College, Srinagar for a period of two years (from April 2014 to April 2016).

\section{Inclusion Criteria}

1. Age 16 years and above.

2. Patients with complete nasolacrimal duct obstruction.

3. Patients with history of dacryocystitis.

\section{Exclusion Criteria}

Patients with history of previous endoscopic DCR, functional obstruction and inadequate followup were excluded from the study.

A proper history regarding age, residence, occupation, duration of symptoms, side of obstruction, previous history of acute dacryocystitis, previous external DCR and presence of any other disease (Systemic or ocular) was taken. An otolaryngologist was also involved in the evaluation to rule out any contraindication to external DCR.

ADC was defined clinically as symptoms of fulminant lacrimal sac inflammation/infection, erythema, pain and discharge for $<2$ weeks' duration prior to initial presentation. CDC was defined clinically as the presence of chronic lowgrade inflammation and associated discharge that had been ongoing or intermittent for $>2$ weeks' duration. ${ }^{9}$

\section{Surgical Technique}

The surgery was performed under local anaesthesia; $2 \%$ Lignocaine with 1:200000 adrenaline was injected at the junction of the inferior orbital margin with the beginning of the anterior lacrimal crest and subcutaneously in the medial canthal area. A curved incision was made $3 \mathrm{~mm}$ medial to the inner canthus with a \#15 Bard Parker blade. A periosteal elevator was used to elevate the periosteum over the anterior lacrimal crest and into the lacrimal sac fossa, elevating the lacrimal sac and exposing the lacrimal bone. An osteotomy about 1 to $1.5 \mathrm{~cm}$ in diameter was created using Kerrison's bone punch and nasal mucosa was exposed. The lacrimal sac and nasal mucosa were incised to create anterior and posterior flaps. A silicone tube was inserted and tied after which the anterior nasal and lacrimal sac mucosal flaps were anastomosed using 6-0 vicryl. The external incision was closed in two layers.

\section{Post-Operative Treatment}

After the surgery, all patients were prescribed an oral antibiotic taken 3 times daily for 5 days after surgery (Augmentin ${ }^{\circledR} 625 \mathrm{mg}$ Tablets co-amoxiclav (Amoxicillin and clavulanic acid)) and moxifloxacin $0.5 \%$, dexamethasone $0.1 \%$ drops (Milflox DM - Sun Pharmaceuticals India) - four times daily for 15 days. Patients were seen at 1 week, 1 month, 3 months and 6 months after surgery. The silicone tubes were kept in situ for $6-16$ weeks. The nasolacrimal system was evaluated anatomically by syringing. Patients were inquired about the symptoms and were asked to rate their satisfaction on a scale of 1 to $10(1=$ extremely dissatisfied to $10=$ extremely satisfied). Surgical success was defined as the resolution of epiphora, no postoperative dacryocystitis and patency on syringing.

\section{Statistical Analysis}

SPSS (Version 20.0) and Microsoft Excel were used to carry out the statistical analysis of data. Continuous variables were summarised as mean and standard deviation and categorical variables as percentage. Data was presented by bar diagrams and pie charts. A $t$-test was used for comparing continuous variables and $\mathrm{P}$ value less than 0.05 was considered statistically significant.

\section{RESULTS}

A total of 76 patients who met the inclusion criteria underwent external DCR. These included 34 (44.7\%) males and 42 (55.2\%) females. The mean age was $58.6 \pm 14$ years.

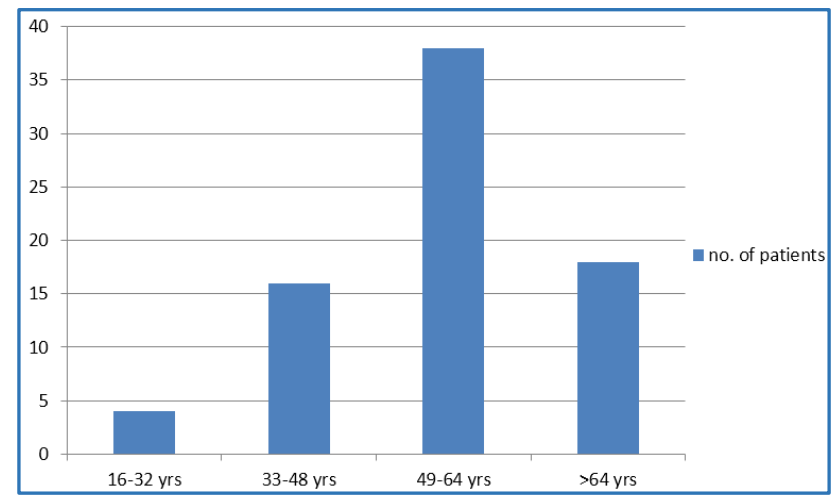

Figure 1. Age Distribution of Patients

$61 \%$ belonged to rural areas, while $39 \%$ were from urban localities. Among males $76.4 \%$ were farmers, while among females majority (85.7\%) were housewives. The commonest symptoms were watering (94.7\%), conjunctivitis (26.3\%) and chronic discharge (48.6\%); 30 patients $(39.4 \%)$ had previous episodes of dacryocystitis, while 46 (60.5\%) had no such history. The mean duration of symptoms was 2.7 years.

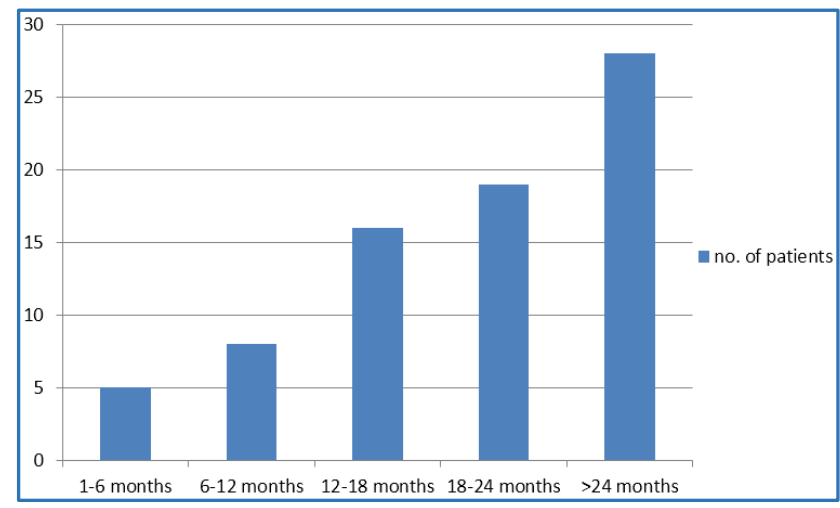

Figure 2. Duration of Symptoms

Left sided obstruction was more common (53.9\%) than right sided (43.4\%), while $2.6 \%$ had bilateral involvement. No significant association of NLDO was seen with other systemic disorders like diabetes (28 patients), hypertension (48 patients) and thyroid disorders (12 patients); 15 patients had previous history of cataract surgery. None of the patients had any history of trauma. 
Significant post-operative nasal bleeding was reported in $4(5.2 \%)$ patients. Wound infection occurred in 2 patients (2.6\%). No other significant complications were present. Patency on syringing and resolution of epiphora was documented in $83.3 \%$ patients with previous history of dacryocystitis and $88.4 \%$ patients without any such history ( $p$ value $>0.05$ ). Patient satisfaction with the surgical outcome is summarised in Figure 3.

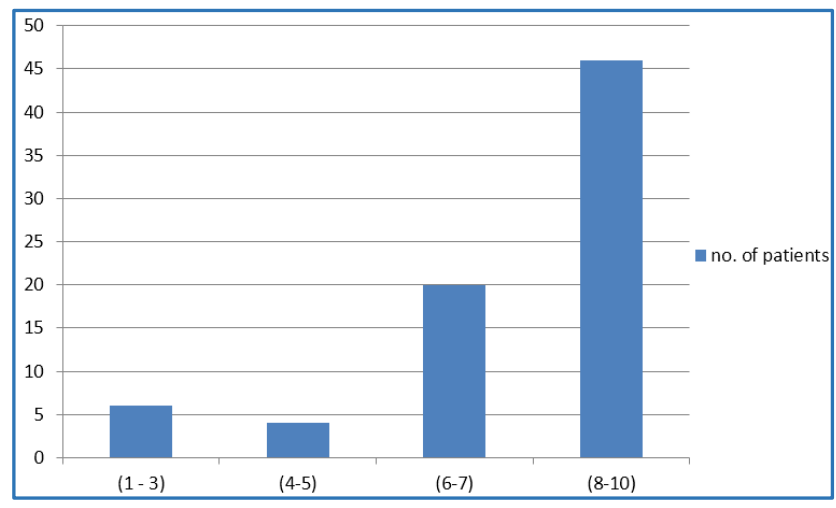

Figure 3. Patient Satisfaction (1 - 10: 1 = Extremely Dissatisfied to 10 = Extremely Satisfied)

\section{DISCUSSION}

Epiphora is one of the commonest complaints of patients attending the eye outpatient departments. On evaluation, majority of these patients have a primary blockage of nasolacrimal duct system. The aim of our study was to evaluate the characteristics and surgical outcome in patients who underwent external DCR, which is considered a standard treatment for NLDO.

This study included $55.2 \%$ females and $44.7 \%$ males, which is similar to study conducted by M. Alnawaiseh et al 2 (Gender [Female:Male] 97 (66.4\%) : 49 (33.6\%)) and most other studies.10,11 The smaller nasolacrimal canal diameter and hormonal factors may be responsible for the increased predilection in females. Majority of the patients were above 50 years of age. Similar results were seen by Yoon et $\mathrm{al}^{12}$ in their study. Left sided obstruction was more common than right sided, which is in harmony with the study conducted by Ivanesi et al,13 Prakash et al ${ }^{14}$ and Gilad et al. ${ }^{8}$ This may be due to the smaller nasolacrimal bony canal in females. Also, it has been found that the nasolacrimal duct and lacrimal fossa form a greater angle on right side than the left side. Most of the patients belonged to rural areas and were involved in outdoor work including farming. Majidae et al ${ }^{15}$ studied the epidemiological characteristics in a group of patients undergoing dacryocystorhinostomy in Northern Iran and found a similar trend. The authors believe that continuous exposure to dust and smoke in these patients may have led to chronic sinusitis and particulate matter settling down in the conjunctival sac and subsequently in the nasolacrimal duct leading to obstruction. The mean duration of symptoms was 2.7 years. Studies by Erdol ${ }^{6}$ et al and Seider et al $^{7}$ suggest that duration of obstruction is a predictive factor for external DCR success rates with earlier surgery offering a greater chance of success.

In this study, external DCR had a success rate of $83.3 \%$ in patients with history of dacryocystitis and $88.4 \%$ in patients without dacryocystitis. This is similar to study conducted by M. Alnawaiseh et al, ${ }^{2}$ in which patients with previous episodes of dacryocystitis had a success rate of $82.7 \%$ and those without previous episodes of dacryocystitis reported a success rate of $83.4 \%$. Gilad et al ${ }^{8}$ observed $94.4 \%$ success rate in patients with dacryocystitis and $86.7 \%$ in patients without such history $(P=0.337)$. In our study, patients who were completely asymptomatic on followup and had patency on postoperative syringing at the end of 6 months were considered as successes. It has been seen that previous episodes of dacryocystitis correlates with shorter duration of nasolacrimal obstruction and epiphora. This shorter duration of epiphora may be responsible for similar success rates in both the groups.

There was no significant association of NLDO and dacryocystitis with other systemic illnesses including diabetes, hypertension and thyroid disorders. We could not find any studies in literature on such association.

Postoperative nasal bleeding and wound infection were the two main complications seen after surgery in our study. No other significant complication was reported suggesting that external DCR was a safe procedure. Majority of the patients were satisfied with the overall results.

Development of minimally invasive endoscopic techniques over the past few years has led to a decrease in the number of external dacryocystorhinostomies performed in specialised centres, especially in developed countries. ${ }^{16,17}$ However, external DCR is a cost effective and equally efficacious procedure with similar success rates and is preferable in cases where endoscopic procedures are contraindicated and in previous failed surgeries. $^{2}$

In conclusion external DCR still remains the treatment of choice for NLDO in our setup with very good postoperative results in patients with or without previous history of dacryocystitis.

\section{REFERENCES}

1. Duggal P, Chakravorty S, Azad RK, et al. An epidemiological study on patients undergoing dacryocystorhinostomy. Indian J Otolaryngol Head Neck Surg 2006;58(4):349-51.

2. Alnawaiseh M, Mihailovic N, Wieneke AC, et al. Long-term outcomes of external dacryocystorhinostomy in the age of transcanalicular microendoscopic techniques. Journal of Ophthalmology Article ID 5918457, 2016;2016; P. 4 doi:10.1155/2016/5918457.

3. Ali MJ, Naik MN, Honavar SG. External dacryocystorhinostomy: tips and tricks. Oman J Ophthalmol 2012;5(3):191-5.

4. Durvasula VSP, Gatland DJ. Endoscopic dacrocystorhinostomy: long-term results and evolution of surgical technique. J Laryngol Otol 2004;118(8):62832.

5. Karim R, Ghabrial R, Lynch T, et al. Comparison of external and endoscopic endonasal dacryocystorhinostomy for acquired nasolacrimal duct obstruction. Clin Ophthalmol 2011;5:979-89.

6. Erdol H, Akyol N, Imamoglu HI, et al. Long-term follow-up of external dacryocystorhinostomy and the factors affecting its success. Orbit 2005;24(2):99-102.

7. Seider N, Kaplan N, Gilboa M, et al. Effect of timing of external dacryocystorhinostomy on surgical outcome. Ophthalmic Plastic and Reconstructive Surgery 2007;23(3):183-6. 
8. Rabina G, Golan S, Neudorfer $M$, et al. External dacryocystorhinostomy: characteristics and surgical outcomes in patients with and without previous dacryocystitis. Journal of Ophthalmology Article ID 287524, 2013;2013; P. 4.

9. Lefebvre DR, Dhar S, Lee I, et al. External dacryocystorhinostomy outcomes in patients with a history of dacryocystitis. Digital Journal of Ophthalmology 2015;21(3):1-22. doi:10.5693/djo.01.2014.08.001.

10. Yang JW, Oh HN. Success rate and complications of endonasal dacryocystorhinostomy with unciformectomy. Graefes Arch Clin Exp Ophthalmol 2012;250(10):150913.

11. Knežević MM, Vlajković GP, Stojković MŽ, et al. Comparison of postoperative pain and satisfaction after dacryocystorhinostomy in patients operated on under local and general anesthesia. Med Sci Monit 2012;18(5):CR265-70.
12. Yoon SW, Yoon YS, Lee SH. Clinical results of endoscopic dacryocystorhinostomy using a microdebrider. Korean J Ophthalmol 2006;20(1):1-6.

13. Ivaniševic $M$, Bojic $L$, Lešin $M$, et al. Primary acquired nasolacrimal duct obstruction: epidemiological analysis of 91 patients. MEJAD 2007;37(1-2):37-41.

14. Prakash R, Babu GRJ, Nagaraj ER, et al. Bacteriological study of dacryocystitis. J Clin Diagn Res 2012;6(4):652-5.

15. Majidaee M, Mohammadi M, Razaee SMR, et al. Patients undergoing dacryocystorhinostomy surgery in northern Iran: An epidemiologic study. Ann Med Health Sci Res 2014;4(3):365-8.

16. Meyer-Rusenberg HW, Emmerich KH. Modern lacrimal duct surgery from the ophthalmological perspective. Deutsches Arzteblatt Int 2010;107(14):254-8.

17. Emmerich KH, Emmerich GM, Steinkogler FJ, et al. How did lacrimal endoscopy influence lacrimal surgery? Klinische Monatsblatter Augenheilkunde 2010;227(7): 559-63. 